Methodology article

\title{
Optimization of immunomagnetic separation for cord blood-derived hematopoietic stem cells Tuija Kekarainen ${ }^{\dagger 1,2}$, Sirkka Mannelin ${ }^{1}$, Jarmo Laine ${ }^{1}$ and Taina Jaatinen* ${ }^{* 1}$
}

\author{
Address: ${ }^{1}$ Finnish Red Cross Blood Service, Helsinki, Finland and ${ }^{2}$ Centre de Recerca en Sanitat Animal (CReSA), Universitat Autònoma de \\ Barcelona, Barcelona, Spain \\ Email: Tuija Kekarainen - tuija.kekarainen@cresa.uab.es; Sirkka Mannelin - sirkka.mannelin@bts.redcross.fi; \\ Jarmo Laine - jarmo.laine@bts.redcross.fi; Taina Jaatinen* - taina.jaatinen@bts.redcross.fi \\ * Corresponding author †Equal contributors
}

Published: 0I August 2006

BMC Cell Biology 2006, 7:30 doi:10.1 |86/I47|-2121-7-30
Received: 03 November 2005

Accepted: 0 I August 2006

This article is available from: http://www.biomedcentral.com/I47I-2/2I/7/30

(c) 2006 Kekarainen et al; licensee BioMed Central Ltd.

This is an Open Access article distributed under the terms of the Creative Commons Attribution License (http://creativecommons.org/licenses/by/2.0), which permits unrestricted use, distribution, and reproduction in any medium, provided the original work is properly cited.

\begin{abstract}
Background: There is a growing interest in cord blood as a source of primitive stem cells with the capacity for multilineage differentiation. Pure cell fractions are needed for the characterization and in vitro expansion of stem cells as well as for their use in preclinical research. However, enrichment of stem cells is challenging due to the lack of stem cell-specific markers and gentle protocols for the isolation of highly pure stem cell fractions. Protocols developed for the enrichment of peripheral blood-derived stem cells have been found to be suboptimal for cord blood.
\end{abstract}

Results: In this study, immunomagnetic cell sorting protocols to purify CD34+, CDI33+ and Lincells from fresh and cryopreserved cord blood were optimized. Reproducible purities of up to $97 \%$ were reached. The selected cells were highly viable having substantial colony-forming potential.

Conclusion: The optimized protocols enable rapid enrichment of highly pure hematopoietic stem cells from both fresh and cryopreserved cord blood.

\section{Background}

Hematopoietic stem cells (HSC), with their unique selfrenewal and differentiation capacity, offer great potential for the treatment of hematological disorders, immunodeficiency and inborn errors of metabolism $[1,2]$. HSCs can be collected from mobilized peripheral blood (PB), bone marrow (BM) and cord blood (CB). Lately, CB has been increasingly utilized because it is readily available, HLA mismatches are better tolerated and there is a decreased risk of graft-versus-host disease when using CB-derived HSCs when compared to the other sources [3]. Even though the cell content of $\mathrm{CB}$ is limited, it has a higher frequency of progenitor cells compared to PB or BM [3-5]. CB-derived CD34+ cells have also been shown to prolifer- ate more rapidly than their counterparts from BM [6], and CB-derived HSCs possess increased engraftment potential when compared to cells from PB or BM $[7,8]$. In addition, recent studies suggest that $\mathrm{CB}$ is a source of non-hematopoietic stem or progenitor cells, such as mesenchymal and endothelial precursors $[9,10]$.

Enrichment of HSCs is based on the expression of certain surface antigens or on the lack of expression of lineagespecific antigens. The most commonly used surface marker for HSC selection is the transmembrane glycoprotein CD34. CD34 is also used to quantify the stem cell content of CB units banked for clinical use [11]. Most, if not all, CD34+ cells express the CD133 glycoprotein on 


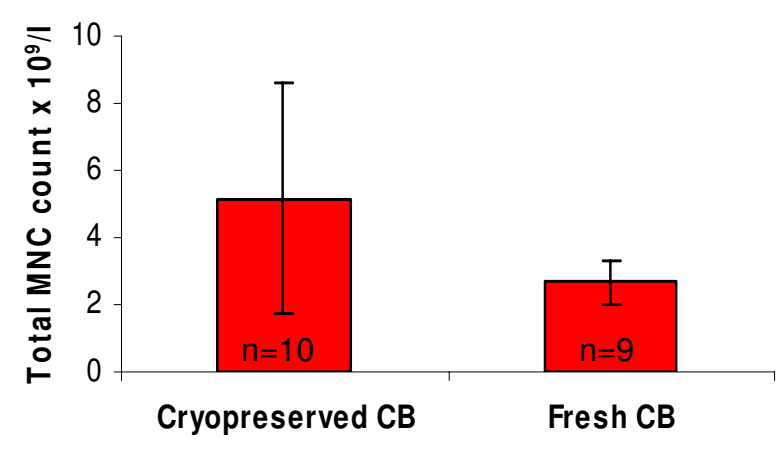

\section{Figure I}

Mean MNC count in cryopreserved and fresh $C B$. The mean MNC concentration for cryopreserved and fresh $C B$ was $5.14 \times 109 / 1$ (range 0.96-10.00, median 4.30, SD = 3.43) and $2.68 \times 109 / /$ (range I.24-3.62, median 2.77, SD = 0.64), respectively. The difference between cryopreserved and fresh $C B$ was not statistically significant $(P=0.06)$. Bars show means and error bars show standard deviations. Abbreviations: MNC, mononuclear cells; $\mathrm{CB}$, cord blood.

their surface. CD133 appears to be expressed on more primitive cells and CD133+ cell grafts have been tested in stem cell transplantation [12-14]. Alternative, but currently poorly characterized Lin- progenitor cells lack lineage-specific markers $[15,16]$. Fluorescence-activated cell sorting and immunomagnetic selection systems utilize antibodies against these cell surface antigens to enrich HSCs. However, the major challenge has been the difficulty to produce highly pure HSC fractions from CB with good recovery. Furthermore, the handling of $\mathrm{CB}$ is challenging due to the relatively high content of thrombocytes and nucleated erythroid precursors which have a negative impact on the mononuclear cell isolation. For these reasons, standardized protocols for PB sample handling and cell separation do not work well for CB. Only few studies have investigated the efficiency of the immunomagnetic selection method used to isolate CD34+ cells from CB. Belvedere et al. compared the results from 49 selections and reported mean CD34+ cell purities of $41 \%$ and $85 \%$ after first and second passage through the separation column, respectively [17]. Melnik et al. report an average purity of $60 \%$ for CB-derived CD34+ cells from 10 separations [18].

In this study, three different protocols were optimized to enrich CD34+, CD133+ and Lin- HSCs with over 90\% purity from both fresh and cryopreserved CB. Cryopreserved CB cells have been considered to be especially challenging in selection procedures because of cell aggregation caused by cell damage during thawing. The used protocols were based on positive selection of cells expressing CD34 and CD133, or on depletion of cells expressing lineagespecific markers. The magnetic cell sorting system MACS was used due to its gentleness and time-effectiveness. Further, the clonogenic capacity of selected HSC populations was determined using the colony-forming unit (CFU) assay.

\section{Results and discussion Handling of CB cells}

The isolation of pure mononuclear cell (MNC) fractions from $\mathrm{CB}$, and subpopulations thereof, brings about a special challenge. This appears to be due to the large number of thrombocytes and erythroid progenitors in $\mathrm{CB}$. In the Ficoll-Paque density gradient, all erythroid cells do not necessarily sediment to the bottom layer, but are retained in the interphase of plasma and Ficoll-Paque. The erythroid cells remaining in the interphase are nucleated progenitors that may hamper the subsequent immunomagnetic selection of HSC populations. Treatment with ammonium chloride or diethylene glycol may be used to deplete red blood cells, but depletion was not performed in this study as the nucleated erythroid progenitors are not easily lyzed and purities up to $97 \%$ were reached without any additional treatment. The unusually slow sedimentation of erythroid cells is not seen when working with PB.

When handling cryopreserved CB cells, aggregation was observed. Aggregation was reduced by replacing ethylenediamine tetraacetic acid (2 mM EDTA, Merck, Darmstadt, Germany) with anticoagulant citrate dextrose solution, formula A (0.6\% ACD/A, Baxter Healthcare, Lessines, Belgium) in the sample buffer. In some cases aggregation was so substantial that the cells needed to be resuspended in DNaseI containing buffer. DNaseI digests the DNA released from dead cells and prevents aggregation. The DNase treatment did not affect the viability or colonyforming potential of selected CB cells. No cell aggregation was seen when handling fresh CB cells.

\section{MNC fraction}

In cryopreserved $\mathrm{CB}$, the mean $\mathrm{MNC}$ concentration was $5.14 \times 10^{9} / 1$ (range 0.96-10.00, SD = 3.43) (Figure 1 ), and the mean platelet concentration was $8.30 \times 10^{9} / 1$ (range 0.00-17.00, SD = 5.46). Cryopreserved CB contained a mean of $0.14 \times 10^{12} / 1$ erythrocytes (range 0.02-0.67, SD $=0.20$ ), and the mean hematocrit was $2 \%$.

Fresh CB contained a mean of $2.68 \times 10^{9} / 1$ MNCs (range 1.24-3.62, SD =0.64) (Figure 1). The difference in MNC concentration between cryopreserved and fresh samples was not statistically significant $(\mathrm{P}=0.06)$. The remarkably high disparity in the standard deviation of MNC concentration between cryopreserved and fresh CB may be due to the processing and freezing of cells performed to bank the 

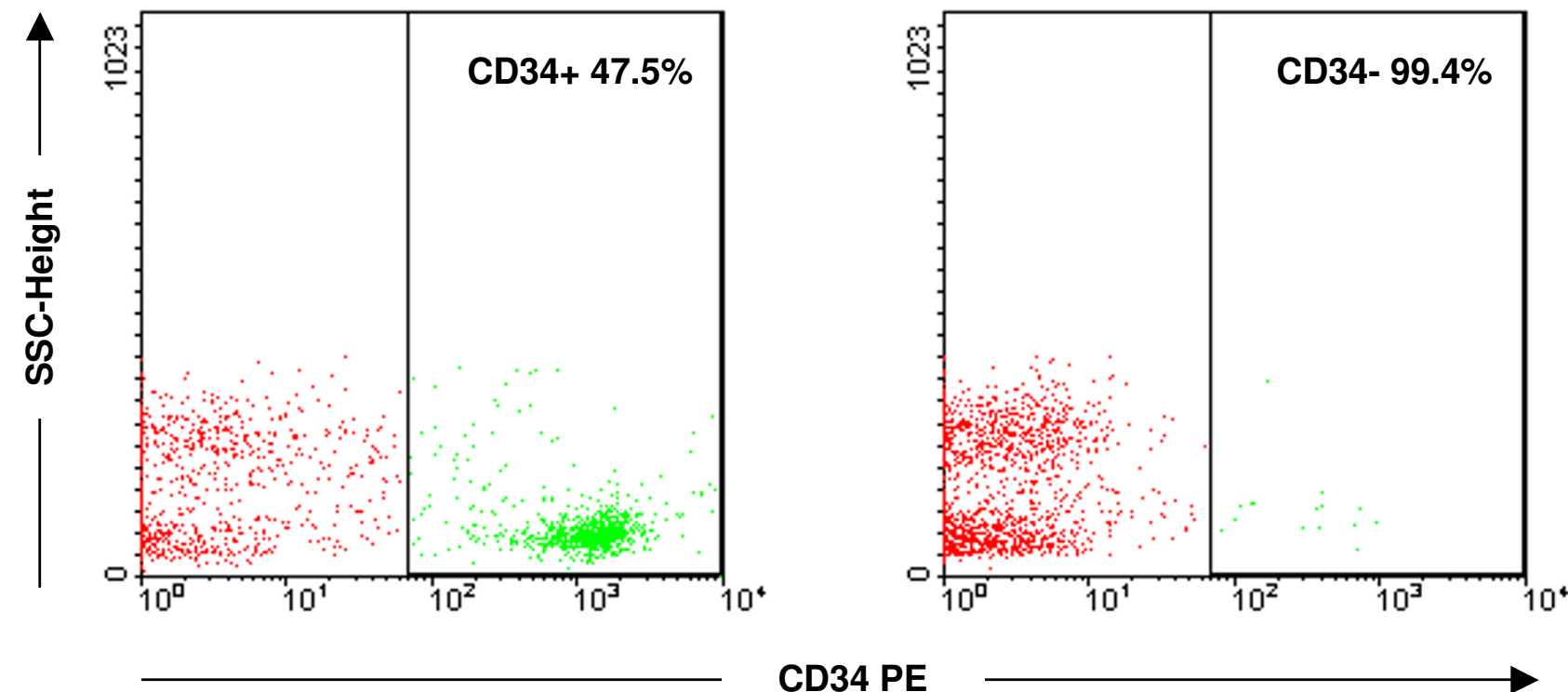

Figure 2

Purity assessment of the CD34+ cell fraction by flow cytometry. The initial purity of CD34+ cells after separation through single column was $47.5 \%$. The CD34- fraction was $99.4 \%$ pure. CD34+ and CD34- cell populations were defined by first gating on forward and side scatter properties excluding platelets and debris. Subsequent gates were set to exclude $>99 \%$ of control cells labeled with isotype-specific antibody. Percentages indicating the purity of isolated cell fractions are shown for both plots. Abbreviations: SSC, side scatter; PE, phycoerythrin.

CB units [19]. The mean concentration was $205.89 \times 10^{9} /$ 1 (range 84.00-505.00, $\mathrm{SD}=130.58$ ) for platelets and $0.12 \times 10^{12} / 1$ (range $0.03-0.50, \mathrm{SD}=0.14$ ) for erythrocytes. The mean hematocrit was $1 \%$.

\section{Immunomagnetic separation of HSC populations}

When using the Direct CD34 Progenitor Cell Isolation Kit with single column separation and the labeling protocol recommended by the manufacturer (Miltenyi Biotec, Bergisch Gladbach, Germany), a purity of less than $50 \%$ was reached for the CD34+ cells (Figure 2). To obtain highly pure CD34+ cells, the immunomagnetic selection method was optimized. Several washing steps (3-10) were tested for single column separation. A purity of $80 \%$ was achieved with extensive washing, but the yield was poor (less than $50 \%$ of the expected yield). Two successive column separations resulted in $77 \%$ purity, but a great number of CD34+ cells were still lost during the process indicating a further need to optimize the protocol. An additional labeling step between the two column separations increased the purity to $>90 \%$ (results for a representative sample shown in figure 3) and resulted in an acceptable yield as well. The optimized two-column method with additional labeling proved reliable and was applied to the separation of both CD34+ and CD133+ cells. The average yield of CD34+ and CD133+ cells from one cord blood unit was $10^{6}$ and $10^{5}$, respectively. The purity of positively selected CD34+/CD133+ cells was reproducibly over $90 \%$ and their negative counterparts were nearly $100 \%$ pure.

Generally, the recovery of CD34+ and CD133+ cells was $0.86 \%$ (range $0.56-1.45, \mathrm{SD}=0.36$ ) and $0.21 \%$ (range $0.04-0.41, \mathrm{SD}=0.12)$, respectively. The recovery of CD34+ cells was higher from fresh CB $(0.97 \%)$ when compared to cryopreserved CB $(0.78 \%)$, although the difference was not statistically significant $(\mathrm{P}=0.54)$. The results are consistent with the study by Almici et al. showing no significant difference in yield or in purity for fresh CB CD34+ cells in comparison to crypreserved cells [20]. This was the case with CD133+ cells as well, the recovery being $0.29 \%$ for fresh CB and $0.12 \%$ for cryopreserved CB $(P=0.11)$. The purities were not affected by the initial percentage of HSC populations in $\mathrm{CB}$. The results of the purity assessment for representative samples of CD34+/-, CD133+/- and Lin-/+ cells are shown in figure 4.

The magnetic sorting of Lin- cells was optimized to find the optimum concentrations for antibodies and magnetic colloids. Lin- cells were separated from the MNC fraction with magnetic cell sorting and the purity of the enriched cell fraction was analyzed by flow cytometry. The average 
A

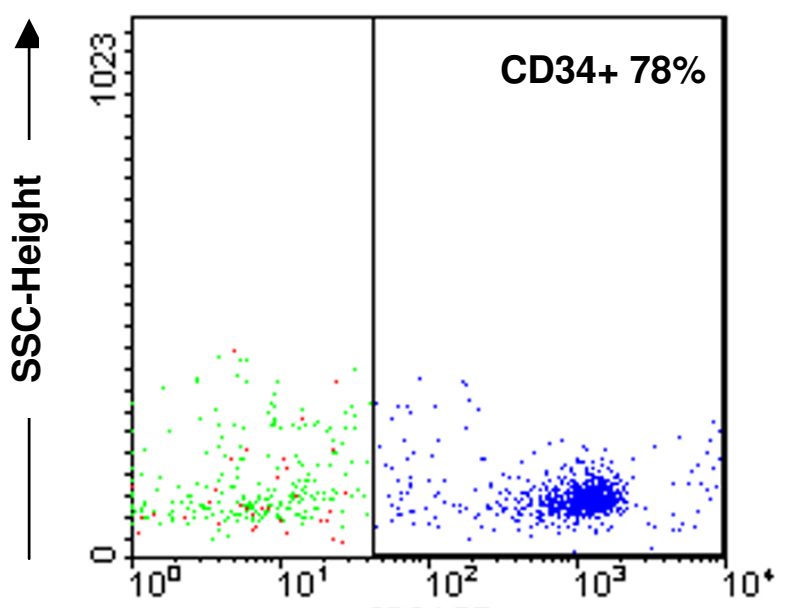

B

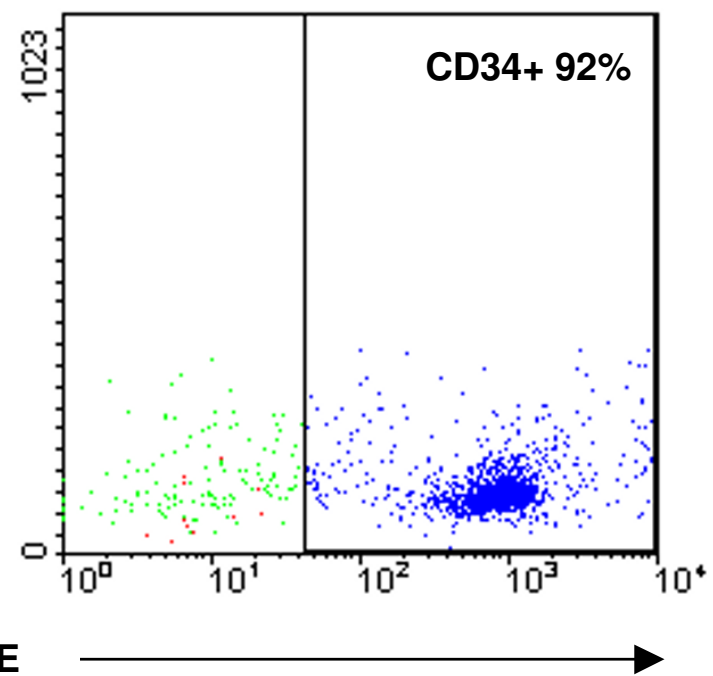

Figure 3

Purity assessment of CD34+ cell fraction after one or two column separations. A) The CD34+ cell fraction was $78 \%$ pure after the first column separation. B) A 92\% pure CD34+ cell faction was obtained by an additional labeling step in connection with a second column separation. CD34+ cell populations were defined by first gating on forward and side scatter properties excluding platelets and debris. Subsequent gates were set to exclude $>99 \%$ of control cells labeled with isotype-specific antibody. Percentages indicating the purity of isolated cell fractions are shown for both plots. Abbreviations: SSC, side scatter; PE, phycoerythrin.

yield of Lin- cells from one cord blood unit was $10^{6}$. The overall recovery of Lin- cells was $0.29 \%$ (range $0.13-0.70$, $\mathrm{SD}=0.21)$, being higher in fresh $\mathrm{CB}$ samples $(0.43 \%)$ than in cryopreserved CB samples $(0.16 \%)$. The difference between fresh and cryopreserved samples was not statistically significant $(P=0.19)$. The mean purity of Lin- cell population was $90 \%$ (range $82-98 \%, \mathrm{SD}=5.00$ ) and it did not differ between fresh and cryopreserved CB units. To assess the effect of antibody concentration on the selection of Lin- cells, varying amounts of the antibody cocktail $(50-100 \mu \mathrm{l} / \mathrm{ml})$ and magnetic colloids $(30-60 \mu \mathrm{l} / \mathrm{ml})$ were tested. The concentration of antibodies and magnetic colloids did not affect the purity of Lin- cells based on flow cytometric analysis.

All the optimized protocols are described in detail in figure 5. The operation time for the selection of CD34+/- and CD133+/- cells using MiniMACS or MidiMACS is approximately 1.5 hours. The operation time for isolation of Lin/+ cells is approximately 45 minutes. The selection can be made more effective with the AutoMACS system developed for high-speed automated cell sorting. The optimized protocols have been developed for enrichment of CB HSCs for research purposes. However, the enrichment of stem and progenitor cells is often necessary in clinical settings. The selected HSCs are increasingly used in trans- plantations and enrichment may be required for depletion of contaminating mature cells or tumor cells. Potentially, the methods described here could be applied to clinical-grade selection using the CliniMACS System that is CE-marked for clinical use in Europe.

With the optimized protocols, a purity of at least $90 \%$ was achieved for CD34+, CD133+ and Lin- cells. Viability was 99\% for all the selected cell types. This demonstrates that the optimized protocols work well for HSC enrichment from both fresh and cryopreserved CB. Fresh CB was easier to handle and the recovery of HSCs was higher from fresh CB. Nonetheless, cryopreserved cord blood is almost exclusively used in clinical settings. Therefore, if one wishes to use selected HSCs, the cells should preferably be isolated on fresh cord blood and cryopreserved after the selection procedure to maximize the recovery of HSCs. HSCs, enriched by the protocols described here, have been used in gene expression studies with great reproducibility and consistency [21].

It has been suggested that the binding of an antibody to the surface of a HSC may influence cell proliferation and differentiation by activating intracellular signaling pathways [14]. An anti-CD34 antibody has been shown to induce tyrosine phosphorylation in BM-derived CD34+ 

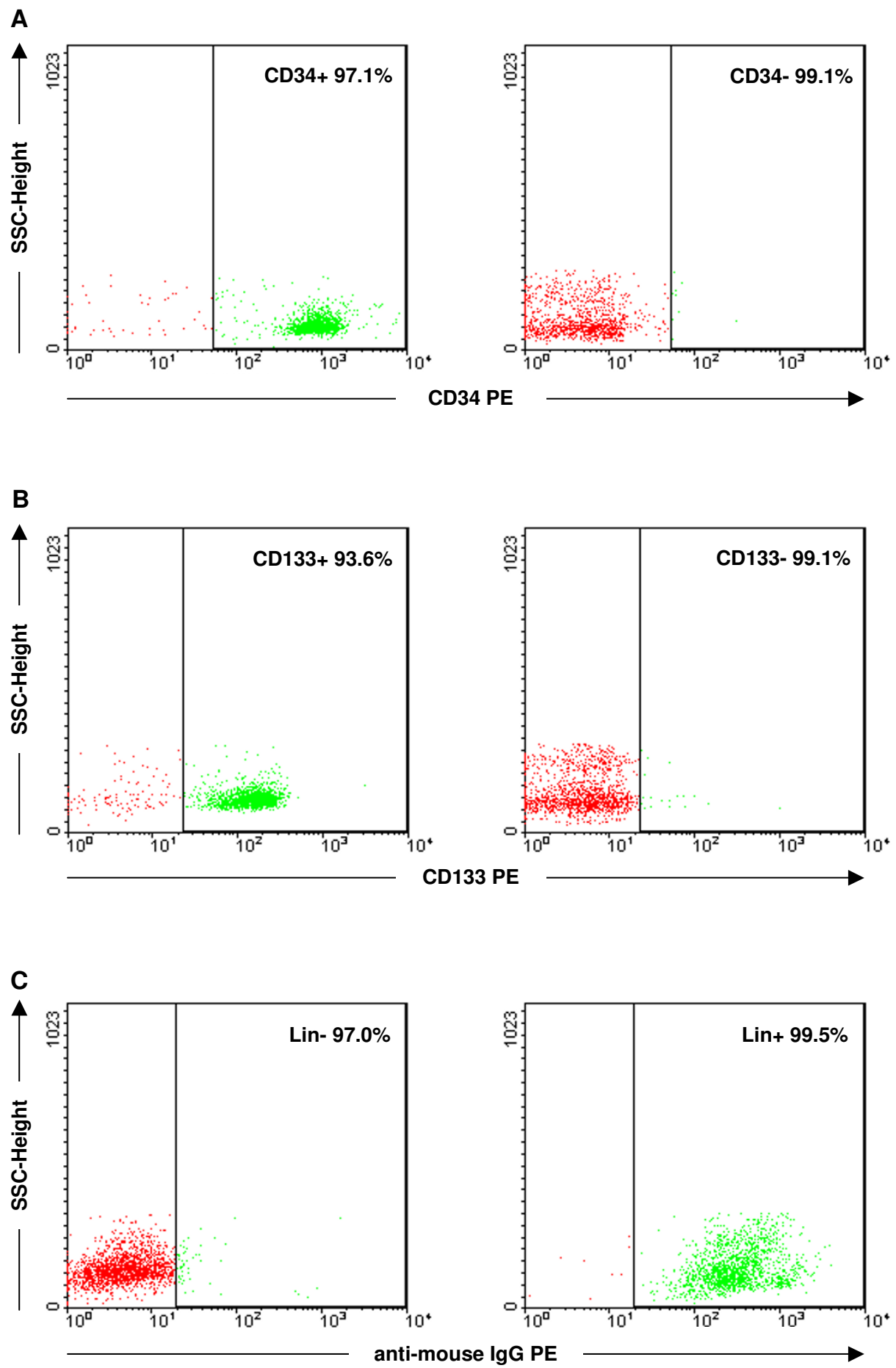

Figure 4

Purity assessment of CD34+/-, CD 133+/- and Lin-/+ cell fractions. A) Purities for CD34+ and CD34- cell factions were 97.I\% and $99.1 \%$, respectively. B) Purities for CDI33+ and CDI33- fractions were $93.6 \%$ and $99.1 \%$, respectively. C) Purities for Lin- and Lin+ cell factions were $97.0 \%$ and $99.5 \%$, respectively. CD34+/-, CDI33+/- cell populations were defined by first gating on forward and side scatter properties excluding platelets and debris. Subsequent gates were set to exclude $>99 \%$ of control cells labeled with isotype-specific antibody. Percentages indicating the purity of isolated cell fractions are shown for both plots. Abbreviations: SSC, side scatter; IgG, immunoglobulin; PE, phycoerythrin. 


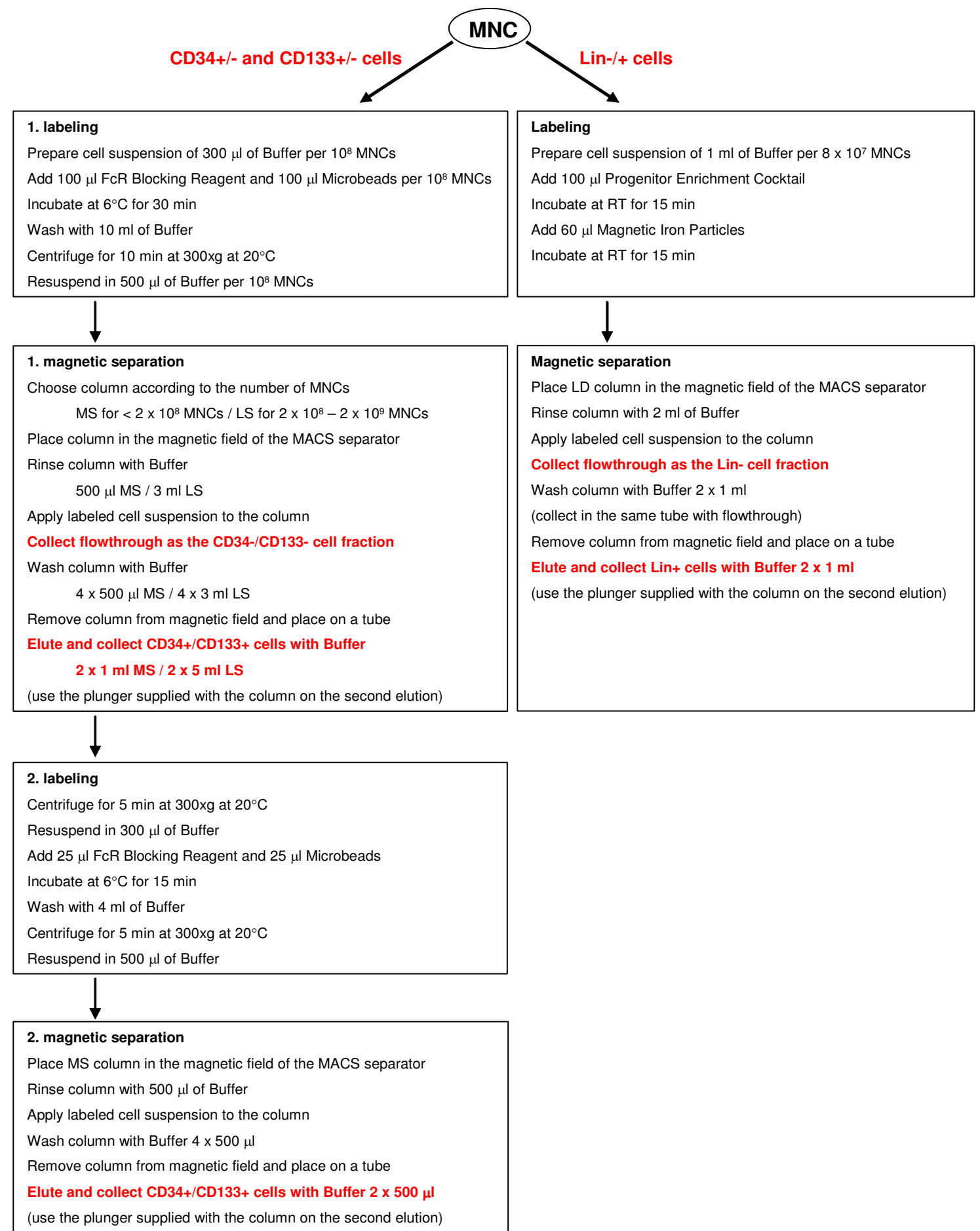

Figure 5

A chart of the optimized protocols to isolate CD34+/-, CDI33+/- and Lin-/+ cells from cord blood. Isolation of CD34/- and CDI33+/- cells was performed using Direct CD34 Progenitor Cell Isolation Kit (\#130-046-702, Miltenyi Biotec) and CDI 33 Cell Isolation Kit (\#I30-050-80I, Miltenyi Biotec), respectively. Lin-/+ cells were isolated using StemSep Human Progenitor Enrichment Kit (\#14056, StemCell Technologies). For all magnetic separations, MACS columns and separators (Miltenyi Biotech) were used. Abbreviations: MNC, mononuclear cells; Buffer, PBS pH 7.2 supplemented with $0.5 \%$ bovine serum albumin and $2 \mathrm{mM}$ EDTA or $0.6 \% \mathrm{ACD} / \mathrm{A}$. 
Table I: Frequency of different types of CFU colonies within CD34+, CDI33+, Lin- and MNC populations.

\begin{tabular}{lllll}
\hline Cell type & CFU-GM & CFU-GEMM & BFU-E & CFU-E \\
\hline CD $34+$ & $58.2 \%$ & $33.2 \%$ & $7.2 \%$ & $1.4 \%$ \\
CDI33+ & $57.4 \%$ & $38.3 \%$ & $4.3 \%$ & $0.0 \%$ \\
Lin- & $43.8 \%$ & $26.3 \%$ & $27.3 \%$ & $2.6 \%$ \\
MNC & $37.8 \%$ & $41.3 \%$ & $15.4 \%$ & $5.5 \%$ \\
\hline
\end{tabular}

cells [22]. However, Lin- cells are selected through negative depletion. Thus, neither antibody binding nor activation of signaling pathways is expected. Further studies on the effect of the interaction between HSCs and the antibodies used for their selection as well as the possible impact of this contact on HSC quality are awaited.

Low number of HSCs in cord blood is a limitation for its use. Ex vivo expansion of HSCs may be used to generate the clinically relevant cell numbers needed for adult patients. However, mature cells may develop during longterm culture and result in a need for reselection of progenitor cells. The optimized protocols can be applied for enrichment of stem and progenitor cells after ex vivo expansion.

\section{Colony forming unit assay}

The CFU assay was used to measure the clonogenic capacity of CD34+, CD133+ and Lin- cells as well as MNCs. Total CFU (CFU-TOT) number was determined as the sum of granulocyte-erythroid-macrophage-megakaryocyte (CFU-GEMM), granulocyte-macrophage (CFU-GM), erythroid (CFU-E) and burst-forming erythroid (BFU-E) colonies. CFU-TOT counts were 84.5, 80.0, 57.3 and 0.5 per 1000 cells for CD34+, CD133+, Lin- and MNCs, respectively. CD34- and CD133- cell populations have shown very limited colony forming potential in our previous studies with CFU-TOT counts of 0.1 and 0.6 per 1000 cells, respectively.

CFU-GM colonies (mean 53.2\%) and CFU-GEMM colonies (mean $32.6 \%$ ) were the most common colony types formed by of CB-derived HSCs. The proportion of different colony types for CD34+, CD133+, Lin- and MNCs is shown in Table 1. BFU-Es represented a mean of $12.9 \%$ of the colony content of HSCs. However, the Lin- cell fraction formed a surprisingly large number of BFU-Es $(27.3 \%)$, probably due to the inefficient removal of erythroid progenitors during the depletion procedure. Very little CFU-E colonies were observed (mean 1.3\%), MNC population being the most efficient in forming them (5.5\%). The high proportion of BFU-E and CFU-E colonies formed by the MNC population reflects the unusual sedimentation of erythroid progenitors in Ficoll-Paque density gradient. The results show that all the selected
HSC populations have substantial clonogenic potential and are highly non-committed. Taken together, the data support the use of traditionally used markers to separate HSC populations until more specific markers are found.

\section{Conclusion}

Immunomagnetic cell sorting enables fast and gentle separation of HSCs. However, the previously reported protocols are not optimal for $\mathrm{CB}$ and result in unsatisfactory purity and yield, indicating a need for optimization of the procedures. With the modified protocols presented here, over $90 \%$ pure HSC fractions can be reproducibly obtained. This is essential for the use of specific hematopoietic progenitor cell types in research and therapeutic applications.

The single most important factor influencing engraftment in HSC transplantation appears to be the nucleated cell content. Even though the cell content is limited in CB and there is no possibility to obtain an additional graft from the same donor, the increased engraftment potential of CB-derived HSCs makes them an appealing alternative for HSCs from PB or BM. It remains to be seen whether the total nucleated cell content or a population of highly pure and specific hematopoietic progenitor cells will prove to be more important for graft potency.

\section{Methods \\ CB units}

Umbilical CB was obtained from informed and consenting donors at the Helsinki University Central Hospital, Department of Obstetrics and Gynaecology. Permit to collect and use donated stem cells has been obtained from the ethics board of the Helsinki University Central Hospital (550/E8/02) and the ethics board of the Finnish Red Cross Blood Service (40/02).

The umbilical cord was clamped according to standard hospital procedure and $\mathrm{CB}$ collections were performed ex utero. CB was collected into a sterile collection bag (Cord Blood Collection system, Medsep Corporation, Covina, USA) containing $25 \mathrm{ml}$ of Citrate Phosphate Dextrose solution. The collection volume varied between 45-105 $\mathrm{ml}$. Some CB units were volume reduced and cryopreserved in a BioArchive system at the Finnish Red Cross Blood Service, Cord Blood Bank as previously described $[16,19]$ and some units were processed freshly within hours from collection. Altogether, 8 cryopreserved and 12 fresh $\mathrm{CB}$ units were used to optimize the protocols. In addition, 10 cryopreserved and 9 fresh CB units were used to test the optimized protocols.

\section{Handling of $C B$ units}

Cryopreserved CB unit was taken from the BioArchive system and kept for 2 minutes in the gas phase of liquid 
nitrogen, 3-5 minutes at room temperature and then in $37^{\circ} \mathrm{C}$ water bath until completely thawed. CB was transferred from the freezing bag into $50 \mathrm{ml}$ tubes containing $10 \mathrm{ml}$ of freezing solution: $2.5 \%$ albumin (Finnish Red Cross, Blood Service, Helsinki, Finland), 50\% NaCl (Baxter Healthcare) and 50\% Gentran40 (Baxter Healthcare). Cells were pelleted by centrifugation at $600 \times \mathrm{g}$ for 10 minutes and the supernatant was discarded. When cell aggregation occurred, the cell pellet was resuspended in $200 \mu \mathrm{l}$ of $1 \mathrm{mg} / \mathrm{ml}$ DNaseI (Sigma-Aldrich, Steinheim, Germany). Cells were then suspended carefully in $100 \mathrm{ml}$ of phosphate-buffered saline (PBS, pH 7.4) supplemented with $0.6 \%$ ACD/A. Fresh CB was diluted 1:4 with PBS supplemented with $2 \mathrm{mM}$ EDTA, to reduce the size and number of cell aggregates and to give better lymphocyte yield in density gradient centrifugation.

MNCs were isolated by density gradient using $15 \mathrm{ml}$ of Ficoll-Paque reagent (Amersham Biociences, Piscataway, USA) and $35 \mathrm{ml}$ of diluted CB. The two-phase system was centrifuged at $400 \times \mathrm{g}$ for 40 minutes. MNCs, collected from the interface of the two phases, were washed twice with PBS. MNC counting was performed by automatic cell counter Sysmex K-1000 (Sysmex Corporation, Kobe, Japan).

\section{Separation of CD34+/CDI33+ cells}

CD34+ and CD133+ cells were enriched through positive selection using MiniMACS or MidiMACS separation systems (Miltenyi Biotec). For the labeling of CD34+ cells, Direct CD34 Progenitor Cell Isolation Kit was used, whereas CD133+ cells were labeled using the CD133 Cell Isolation Kit. $100 \mu \mathrm{l}$ of FcR Blocking Reagent, to inhibit unspecific or Fc-receptor mediated binding, and $100 \mu \mathrm{l}$ of CD34/CD133 MicroBeads for magnetic labeling of cells were added per $10^{8}$ cells, as per manufacturer's recommendations.

MS or LS MACS affinity columns were used depending on the number of MNCs. MS column was used for up to $2 \times$ $10^{8} \mathrm{MNCs}$, and LS column was used for $2 \times 10^{8}$ to $2 \times 10^{9}$ of MNCs. Labeled cell suspension was subjected to immunomagnetic separation where magnetically labeled cells retain in the column while the unlabeled cells pass through the column. After several washes, the column was removed from the magnet and the retained CD34+ or CD133+ cells were eluted with 1-5 ml of PBS supplemented with $0.5 \%$ bovine serum albumin and $2 \mathrm{mM}$ EDTA. CD34+ and CD133+ cells were subjected to one or two rounds of separation and their negative counterparts were collected for control purposes. In the two-column system, an additional labeling step between the column separations was tested, using $25 \mu$ l of both FcR Blocking Reagent and MicroBeads. The optimum purity and yield was obtained when using the additional labeling step in connection with the two-column system.

\section{Separation of Lin- cells}

To enrich progenitor cells, lineage committed cells were depleted. MNCs $\left(8 \times 10^{7} / \mathrm{ml}\right)$ were labeled with Progenitor Enrichment Cocktail containing antibodies against CD2, CD3, CD14, CD16, CD19, CD24, CD56, CD66b and Glycophorin A (StemCell Technologies, Vancouver, Canada) at room temperature for 15 minutes. Subsequently, the cell suspension was incubated with magnetic iron particles at room temperature for 15 minutes. Varying concentrations of StemSep Progenitor Enrichment Cocktail $(100 \mu \mathrm{l} / \mathrm{ml}, 75 \mu \mathrm{l} / \mathrm{ml}$, and $50 \mu \mathrm{l} / \mathrm{ml})$ and magnetic iron particles $(60 \mu \mathrm{l} / \mathrm{m}, 45 \mu \mathrm{l} / \mathrm{ml}$, and $30 \mu \mathrm{l} / \mathrm{ml})$ were tested. Cell suspension was loaded into MACS LD column (Miltenyi Biotec) and unlabeled cells passing through the column were collected (Lin- fraction). The column was then washed twice with $1 \mathrm{ml}$ of buffer and the remaining Lin+ cells were collected for control purposes. The conditions resulting in optimal separation of Lincells were $100 \mu \mathrm{l}$ of Progenitor Enrichment Cocktail and $60 \mu \mathrm{l}$ of magnetic iron particles per $8 \times 10^{7} / \mathrm{ml} \mathrm{MNCs}$, as recommended by the manufacturer.

\section{Purity}

To determine the purity of CD34+/- and CD133+/- cell fractions, $1 \times 10^{5}$ cells were labeled with fluorescein isothiocyanate (FITC)-conjugated anti-CD45 (clone 2D1, Becton Dickinson, Franklin Lakes, USA) and phycoerythrin (PE)-conjugated anti-CD34 (clone 345802 Becton Dickinson) or PE-conjugated anti-CD133 (clone 293C3, Miltenyi Biotec) monoclonal antibodies at $4{ }^{\circ} \mathrm{C}$ for 15 minutes. Lin-/+ cells were labeled with PE-conjugated anti-mouse immunoglobulin specific polyclonal antibody (BD Biosciences, San Jose, USA). Platelets were detected with PE-conjugated anti-CD41a monoclonal antibody (BD Biosciences, San Jose, USA). Isotype-identical monoclonal antibodies served as controls. Labeled cells were analyzed using Becton Dickinson FACSCalibur $^{\mathrm{TM}}$ with a $488 \mathrm{~nm}$ blue argon laser. Fluorescence was measured using 530/30 nm (FITC) and 585/42 nm (PE) bandpass filters. Data were analyzed using the ProCOUNT $^{\mathrm{TM}}$ software (BD Biosciences) or Windows Multiple Document Interface for Flow Cytometry, WinMDI version 2.8 [23]. CD34+, CD133+ and Lin- cell populations were defined by first gating on forward and side scatter properties excluding platelets and debris. Subsequent gates were set to exclude $>99 \%$ of control cells labeled with isotype-specific antibody.

\section{Colony forming unit assay}

MNCs $\left(1 \times 10^{5}\right)$ and enriched HSCs $\left(2 \times 10^{3}\right)$ suspended in $300 \mu \mathrm{l}$ Iscove's Modified Dulbecco's Medium supplemented with $2 \%$ fetal bovine serum (Gibco/Invitrogen, 
Paisley, United Kingdom) were mixed vigorously with 3 ml of MethoCult GF H4434 containing recombinant cytokines and erythropoietin (StemCell Technologies). The cells in MethoCult medium were plated in duplicate into sterile $35 \mathrm{~mm}$ petri dishes, and colonies were scored according to their morphological characteristics by light microscopy after a 14-day culture. Cell culture and colony scoring were performed according to accredited methodology (Finnish Cord Blood Bank, Finnish Red Cross Blood Service, Helsinki, Finland) following international standards [24,25]. The CFU assay was performed in triplicate for each cell type (CD34+, CD133+, Lin- and MNC).

\section{Statistical analysis}

For statistical analysis of total MNC counts between cryopreserved and fresh $\mathrm{CB}$ samples, the non-parametric Mann-Whitney test was used, as the MNC counts were not normally distributed. The two groups, cryopreserved and fresh $\mathrm{CB}$, were considered independent as they have been produced using different protocols. The recovery of CD34+, CD133+ and Lin- cells between cryopreserved and fresh $\mathrm{CB}$ was compared in independent samples by the $t$ test and equality of variances was checked by Levene's test. When the assumption of equality was not satisfied, as with Lin- cells, the t test for non-equal variances was used to compensate the lack of homoscedasticity. P values less than 0.05 were considered statistically significant. The analyses were performed by Microsoft Excel and SPSS 12.0.1.

\section{Authors' contributions}

TK and TJ contributed equally to the work and participated in the design of the study, optimized the experimental procedures, performed the mononuclear cell fractionation, HSC selections and flow cytometric analyses, and drafted the manuscript. SM performed the CFU assays and participated in the interpretation of data. JL participated in the design and coordination of the study, and assisted in drafting the manuscript. All authors read and approved the final manuscript.

\section{Acknowledgements}

We are very grateful to Finnish Red Cross Blood Service Cord Blood Bank for providing the cord blood samples. We thank Hanna Salo for assistance with statistical analyses and Heidi Hemmoranta for helpful comments on the manuscript.

\section{References}

I. Bhattacharya A, Slatter MA, Chapman CE, Barge D, Jackson A, Flood T], Abinun M, Cant AJ, Gennery AR: Single centre experience of umbilical cord stem cell transplantation for primary immunodeficiency. Bone Marrow Transplant 2005, 36:295-299.

2. Peters C, Steward CG: Hematopoietic cell transplantation for inherited metabolic diseases: an overview of outcomes and practice guidelines. Bone Marrow Transplant 2003, 31:229-239.

3. Grewal SS, Barker JN, Davies SM, Wagner JE: Unrelated donor hematopoietic cell transplantation: marrow or umbilical cord blood? Blood 2003, 101:4233-4244.
4. Broxmeyer HE, Douglas GW, Hangoc G, Cooper S, Bard J, English D, Arny M, Thomas L, Boyse EA: Human umbilical cord blood as a potential source of transplantable hematopoietic stem/progenitor cells. Proc Natl Acad Sci U S A 1989, 86:3828-3832.

5. Broxmeyer HE, Hangoc G, Cooper S, Ribeiro RC, Graves V, Yoder M, Wagner J, Vadhan-Raj S, Benninger L, Rubinstein P, .: Growth characteristics and expansion of human umbilical cord blood and estimation of its potential for transplantation in adults. Proc Natl Acad Sci U S A 1992, 89:4 109-4II 3.

6. Hao QL, Shah AJ, Thiemann FT, Smogorzewska EM, Crooks GM: A functional comparison of CD34 + CD38- cells in cord blood and bone marrow. Blood 1995, 86:3745-3753.

7. Vormoor J, Lapidot T, Pflumio F, Risdon G, Patterson B, Broxmeyer HE, Dick JE: Immature human cord blood progenitors engraft and proliferate to high levels in severe combined immunodeficient mice. Blood 1994, 83:2489-2497.

8. Hogan CJ, Shpall EJ, McNulty O, McNiece I, Dick JE, Shultz LD, Keller $\mathrm{G}$ : Engraftment and development of human CD34(+)enriched cells from umbilical cord blood in NOD/LtSz-scid/ scid mice. Blood 1997, 90:85-96.

9. Tondreau T, Meuleman N, Delforge A, Dejeneffe M, Leroy R, Massy M, Mortier C, Bron D, Lagneaux L: Mesenchymal Stem Cells Derived from CDI33-Positive Cells in Mobilized Peripheral Blood and Cord Blood: Proliferation, Oct4 Expression, and Plasticity. Stem Cells 2005, 23: I I05-IIII2.

10. Yang C, Zhang ZH, Li ZJ, Yang RC, Qian GQ, Han ZC: Enhancement of neovascularization with cord blood CDI33+ cellderived endothelial progenitor cell transplantation. Thromb Haemost 2004, 9 1: I 202-1212.

II. Aroviita P, Teramo K, Hiilesmaa V, Kekomaki R: Cord blood hematopoietic progenitor cell concentration and infant sex. Transfusion 2005, 45:613-62I.

12. Yin AH, Miraglia S, Zanjani ED, Almeida-Porada G, Ogawa M, Leary AG, Olweus ], Kearney ], Buck DW: ACI33, a novel marker for human hematopoietic stem and progenitor cells. Blood 1997, 90:5002-5012.

13. Pasino M, Lanza T, Marotta F, Scarso L, De Biasio P, Amato S, Corcione A, Pistoia V, Mori PG: Flow cytometric and functional characterization of $\mathrm{ACI} 33+$ cells from human umbilical cord blood. Br J Haematol 2000, 108:793-800.

14. Lang P, Bader P, Schumm M, Feuchtinger T, Einsele H, Fuhrer M, Weinstock C, Handgretinger R, Kuci S, Martin D, Niethammer D, Greil J: Transplantation of a combination of CDI33+ and CD34+ selected progenitor cells from alternative donors. $\mathrm{Br}$ J Haematol 2004, 1 24:72-79.

15. Nakamura Y, Ando K, Chargui J, Kawada H, Sato T, Tsuji T, Hotta T, Kato S: Ex vivo generation of CD34(+) cells from CD34(-) hematopoietic cells. Blood 1999, 94:4053-4059.

16. Preffer FI, Dombkowski D, Sykes M, Scadden D, Yang YG: Lineagenegative side-population (SP) cells with restricted hematopoietic capacity circulate in normal human adult blood: immunophenotypic and functional characterization. Stem Cells 2002, 20:417-427.

17. Belvedere O, Feruglio C, Malangone W, Bonora ML, Donini A, Dorotea L, Tonutti E, Rinaldi C, Pittino M, Baccarani M, Del Frate G, Biffoni F, Sala P, Hilbert DM, Degrassi A: Phenotypic characterization of immunomagnetically purified umbilical cord blood CD34+ cells. Blood Cells Mol Dis 1999, 25: I 40-। 45.

18. Melnik K, Nakamura M, Comella K, Lasky LC, Zborowski M, Chalmers J]: Evaluation of eluents from separations of CD34+ cells from human cord blood using a commercial, immunomagnetic cell separation system. Biotechnol Prog 200I, 17:907-916.

19. Aroviita P, Teramo K, Westman P, Hiilesmaa V, Kekomaki R: Associations among nucleated cell, CD34+ cell and colony-forming cell contents in cord blood units obtained through a standardized banking process. Vox Sang 2003, 84:2 19-227.

20. Almici C, Carlo-Stella C, Wagner JE, Mangoni L, Garau D, Re A, Giachetti R, Cesana C, Rizzoli V: Clonogenic capacity and ex vivo expansion potential of umbilical cord blood progenitor cells are not impaired by cryopreservation. Bone Marrow Transplant 1997, 19:1079-1084.

21. Jaatinen $T$, Hemmoranta $H$, Hautaniemi S, Niemi J, Nicorici D, Laine J, Yli-Harja O, Partanen J: Global Gene Expression Profile of Human Cord Blood-Derived CDI33+ Cells. Stem Cells 2006, 24:63I-64I. 
22. Tada J, Omine M, Suda T, Yamaguchi N: A common signaling pathway via Syk and Lyn tyrosine kinases generated from capping of the sialomucins CD34 and CD43 in immature hematopoietic cells. Blood 1999, 93:3723-3735.

23. Windows Multiple Document Interface for Flow Cytometry (WinMDI) version 2.82006 [http://facs.scripps.edu/soft ware.html].

24. StemCell Technologies: MethoCult GF H84434. StemCell Technologies Technical Manual 2006, Version I.0.0:I-4.

25. Nissen-Druey C, Tichelli A, Meyer-Monard S: Human hematopoietic colonies in health and disease. Acta Haematol 2005, I I 3:5-96.

Publish with Bio Med Central and every scientist can read your work free of charge

"BioMed Central will be the most significant development for disseminating the results of biomedical research in our lifetime. "

Sir Paul Nurse, Cancer Research UK

Your research papers will be:

- available free of charge to the entire biomedical community

- peer reviewed and published immediately upon acceptance

- cited in PubMed and archived on PubMed Central

- yours - you keep the copyright

Submit your manuscript here:

http://www.biomedcentral.com/info/publishing_adv.asp
BioMedcentral 